\title{
Poor Dental Status and Oral Hygiene Practices in Institutionalized Older People in Northeast Brazil
}

\author{
Luciene Ribeiro Gaião, ${ }^{1}$ Maria Eneide Leitão de Almeida, ${ }^{2}$ José Gomes Bezerra Filho, ${ }^{1}$ \\ Peter Leggat, ${ }^{3,4}$ and Jorg Heukelbach ${ }^{1,3}$ \\ ${ }^{1}$ Department of Community Health, School of Medicine, Federal University of Ceará (UFC), Fortaleza, Ceará 60430-140, Brazil \\ ${ }^{2}$ Department of Clinical Dentistry, School of Pharmacy, Dentistry and Nursing, Federal University of Ceará (UFC), \\ Fortaleza, Ceará 60430-140, Brazil \\ ${ }^{3}$ School of Public Health, Tropical Medicine and Rehabilitation Sciences, James Cook University, Townsville 4811, Australia \\ ${ }^{4}$ School of Public Health, University of the Witwatersrand, Johannesburg 2050, South Africa
}

Correspondence should be addressed to Jorg Heukelbach, heukelbach@web.de

Received 2 July 2008; Revised 14 December 2008; Accepted 9 March 2009

Recommended by W. Murray Thomson

In this study we describe the dental status and oral hygiene practices in institutionalized older people and identify factors associated with poor dental status. A cross-sectional study was performed in a nursing home in Fortaleza, the capital of Ceará State (northeast Brazil). The number of decayed, missing, and filled teeth (DMFT) was assessed in the residents of the nursing home $(n=167$; mean age $=76.6$ years). The mean DMFT value was 29.7 ; the mean number of missing teeth was 28.4 . Ninety-three $(58.1 \%)$ were edentulous. Almost $90 \%$ practiced oral hygiene, but only about half used a toothbrush. Only $8 \%$ had visited a dentist in the preceding three months. Most of the variables regarding oral hygiene habits (such as the use of toothbrush, frequency of oral hygiene per day, regular tooth brushing after meals) did not show any significant association with the DMFT. In multivariate regression analysis, age, general literacy level, and practice of oral hygiene were independently associated with the DMFT $\left(R^{2}=\right.$ 0.13). Institutionalized older people in northeast Brazil have poor dental status, and oral hygiene practices are insufficient. Dental health education is needed focusing on the special needs of this neglected and socioeconomically deprived population to improve their quality of life.

Copyright (C) 2009 Luciene Ribeiro Gaião et al. This is an open access article distributed under the Creative Commons Attribution License, which permits unrestricted use, distribution, and reproduction in any medium, provided the original work is properly cited.

\section{Introduction}

Throughout the world, the proportion of older people in the general population has increased in recent years. In addition to other general health issues there are tremendous implications for oral health. In older people there is a high level of tooth loss, dental caries, periodontal disease, xerostomia and cancer $[1,2]$. In addition, poor oral health and poor general health are often interrelated.

There are several studies on the dental status of institutionalized older people throughout the world. For example, studies have been reported from the United States [3], Australia [4, 5], Canada [6], India [7], Italy [8, 9], Greece [10], Croatia [11], the Fiji Islands [12], Hong Kong [13] and Singapore [14], indicating that the dental status of institutionalized older people is generally poor, with a high decayed, missing, or filled teeth (DMFT) index.

In Brazil, the demographic transition has been particularly accelerated, which has been associated with a higher demand for long care facilities for older people. Despite this, data on institutionalized older people from Brazil are scarce. Some reports from south Brazil suggest that the oral health of institutionalized older people is poor [15-17]. Data on the dental status of institutionalized older people from the northeast of the country, which has different socioeconomic and cultural characteristics from the south and is considered the poorest region of the country, are virtually nonexistent. In particular, there is no data on the factors that contribute to poor oral health status in these special populations and the state of oral hygiene practices. To assist 
TABLE 1: Demographic and socioeconomic characteristics of institutionalized older people in northeast Brazil.

\begin{tabular}{|c|c|c|c|c|}
\hline & Total N $(\%)^{*}$ & Dentate N $(\%)^{*}$ & Edentulous N $(\%)^{*}$ & $P$ value (dentates versus edentulous) \\
\hline \multicolumn{5}{|l|}{ Sex } \\
\hline Male & $81(50.6 \%)$ & $43(53.1 \%)$ & $38(46.9 \%)$ & \multirow{2}{*}{$P=.004$} \\
\hline Female & $79(49.4 \%)$ & $24(30.4 \%)$ & $55(69.6 \%)$ & \\
\hline \multicolumn{5}{|l|}{ Age } \\
\hline $65-74$ years & $75(46.9 \%)$ & $33(44.0 \%)$ & $42(56.0 \%)$ & \multirow{3}{*}{$P=.7$} \\
\hline $75-84$ years & $56(35.0 \%)$ & $21(37.5 \%)$ & $35(62.5 \%)$ & \\
\hline$\geq 85$ years & $29(18.1 \%)$ & $13(44.8 \%)$ & $16(55.2 \%)$ & \\
\hline \multicolumn{5}{|l|}{ Marital status } \\
\hline Single/widowed/divorced & $141(88.1 \%)$ & $54(38.3 \%)$ & $87(61.2 \%)$ & \multirow{2}{*}{$P=.01$} \\
\hline Married & $19(11.9 \%)$ & $13(68.4 \%)$ & $6(31.6 \%)$ & \\
\hline \multicolumn{5}{|l|}{ Time in institution } \\
\hline $0-5$ years & $85(53.1 \%)$ & $42(49.4 \%)$ & $43(50.6 \%)$ & \multirow{3}{*}{$P=.1$} \\
\hline $6-10$ years & $32(20.0 \%)$ & $12(37.5 \%)$ & $20(62.5 \%)$ & \\
\hline$>10$ years & $43(26.9 \%)$ & $13(30.2 \%)$ & $30(69.8 \%)$ & \\
\hline \multicolumn{5}{|l|}{ General literacy level } \\
\hline Illiterate & $65(40.6 \%)$ & $26(40.0 \%)$ & $39(60.0 \%)$ & \multirow{2}{*}{$P=.7$} \\
\hline Literate & 95 (59.4\%) & $41(43.2 \%)$ & $54(56.8 \%)$ & \\
\hline
\end{tabular}

*\% in "total" column are column percentages; \% in "dentate" and "edentulous" columns are row percentages.

in filling this gap, a cross-sectional study was performed assessing oral status and hygiene practices of residents in a nursing home in Fortaleza, a capital city in northeast Brazil.

\section{Methods}

This cross-sectional study was performed in the institution "Lar Torres de Melo", a nursing home in Fortaleza, capital of Ceará State in northeast Brazil. Fortaleza has a population of approximately 2,4 million people. "Lar Torres de Melo" is the largest institution for older people in the State and typically would have about 220 residents. All individuals residing in the institution and who matched the WHO definition for older people were eligible for the study. Of the 220 residents, $167(75.9 \%)$ met this inclusion criterion of $\geq 65$ years of age.

The study consisted of a clinical oral examination; a structured interview using a pretested questionnaire to assess oral hygiene practices, such as frequency of oral hygiene, type of hygiene, and visits to dentists; the analysis of the patients' records to obtain data on age, marital status, time in the institution, general literacy level (years of schooling), and retirement status. Professional carers were interviewed in some cases, particularly when the older people were not in the physical or mental condition to answer questions. The clinical oral examination consisted of assessment of the DMFT using Brazilian standard procedures, which were similar to WHO standards [18].

To reduce interobserver bias, all clinical examinations were done by a single investigator, an experienced dentist. Detailed clinical data, including periodontal diseases and the use and need of prosthesis of the study population, are published elsewhere [19].
Data were double entered into a database using the Epi Info software package (Version 6.04d, Centers for Disease Control and Prevention, Atlanta, USA) and checked for entry errors. After bivariate analysis using t test and Kruksal Wallis test, appropriate multiple linear regression, using the DMFT as the dependent variable, was performed. All variables with a significance level of $P<.25$ were included in the regression analysis. Backward elimination was used. Regression analysis was done with STATA ${ }^{\text {TM }}$ software (Version 8; Stata Corporation, College Station, Tex, USA). The study was approved by the Ethical Review Board of the Federal University of Ceará, Brazil. Informed written consent was obtained from study participants or the appropriate legal guardians.

\section{Results}

One hundred and sixty individuals were included in the study (95.8\% of the target population). The mean age was 76.6 years ( standard deviation $=8.6$ years), with a maximum age of 100 years. The mean time of living in the institution was 8.2 years (range: 1 month-50 years). Many were illiterate. Demographic and socioeconomic variables are detailed in Table 1.

Ninety-three $(58.1 \%)$ were edentulous, and the mean number of teeth missing was 28.4. The mean DMFT of all study participants was 29.7 ( $\mathrm{SD}=4.4$; edentulous participants were allocated a DMFT of 32). The mean DMFT for the 67 dentate individuals was $26.6(\mathrm{SD}=5.3) ; 16(23.9 \%)$ of these presented a DMFT of 32. Of all participants, 109 $(68.1 \%)$ had a DMFT of 32, which meant that they did not have a single healthy tooth.

Oral hygiene practices are detailed in Table 2. Almost $90 \%$ practiced oral hygiene, and more than three-quarters of these did not need the help of a professional carer. Only about half of the study participants used a toothbrush. 
TABLE 2: Oral hygiene practices of institutionalized older people in northeast Brazil $(\mathbf{n}=160)$.

\begin{tabular}{|c|c|c|c|c|}
\hline & Total N (\%) & Dentates N (\%) & Edentulous N (\%) & $\begin{array}{l}P \text { value (dentates } \\
\text { versus edentulous) }\end{array}$ \\
\hline \multicolumn{5}{|c|}{ Practices any type of oral hygiene } \\
\hline No & $17(10.6 \%)$ & $5(7.5 \%)$ & $12(12.9 \%)$ & \multirow{2}{*}{$P=.3$} \\
\hline Yes & $143(89.4 \%)$ & $62(92.5 \%)$ & $81(87.1 \%)$ & \\
\hline \multicolumn{5}{|c|}{ Who performs the oral hygiene? ${ }^{\dagger}$} \\
\hline Patient & $111(77.6 \%)$ & $49(79.0 \%)$ & $62(76.5 \%)$ & \multirow{2}{*}{$P=.7$} \\
\hline Carer & $32(22.4 \%)$ & $13(21.0 \%)$ & $19(23.5 \%)$ & \\
\hline \multicolumn{5}{|l|}{ Use of a toothbrush } \\
\hline No & $78(48.7 \%)$ & $33(49.3 \%)$ & $45(48.4 \%)$ & \multirow{2}{*}{$P=.9$} \\
\hline Yes & $82(51.3 \%)$ & $34(50.7 \%)$ & $48(51.6 \%)$ & \\
\hline \multicolumn{5}{|c|}{$\begin{array}{l}\text { Received health education regarding oral } \\
\text { hygiene* }\end{array}$} \\
\hline No & $54(34.2 \%)$ & $27(40.3 \%)$ & $27(29.0 \%)$ & \multirow{2}{*}{$P=.16$} \\
\hline Yes & $104(65.8 \%)$ & $40(59.7 \%)$ & $64(68.8 \%)$ & \\
\hline \multicolumn{5}{|c|}{ Regular toothbrushing after meals } \\
\hline No & $70(43.8 \%)$ & $37(55.2 \%)$ & $33(35.5 \%)$ & \multirow{2}{*}{$P=.01$} \\
\hline Yes & $90(56.2 \%)$ & $30(44.8 \%)$ & $60(64.5 \%)$ & \\
\hline \multicolumn{5}{|c|}{ Frequency of oral hygiene per day } \\
\hline Never & $17(10.6 \%)$ & $10(14.9 \%)$ & $7(7.5 \%)$ & \multirow{4}{*}{$P=.4$} \\
\hline Once & $41(25.6 \%)$ & $15(22.4 \%)$ & $26(28.0 \%)$ & \\
\hline Twice & $66(41.3 \%)$ & $26(38.8 \%)$ & $40(43.0 \%)$ & \\
\hline Three times or more & $36(22.5 \%)$ & $16(23.9 \%)$ & $20(21.5 \%)$ & \\
\hline \multicolumn{5}{|l|}{ Cleaning the tongue } \\
\hline No & $85(53.1 \%)$ & $39(58.2 \%)$ & $46(49.5 \%)$ & \multirow[t]{2}{*}{$P=.3$} \\
\hline Yes & $75(46.9 \%)$ & $28(41.8 \%)$ & $47(50.5 \%)$ & \\
\hline \multicolumn{5}{|c|}{ Visit to a dentist in the last 3 months* } \\
\hline No & $144(91.7 \%)$ & $56(83.6 \%)$ & $88(94.6 \%)$ & \multirow{2}{*}{$P=.1$} \\
\hline Yes & $13(8.3 \%)$ & $8(11.9 \%)$ & $5(5.4 \%)$ & \\
\hline \multicolumn{5}{|c|}{ Reason for the last visit to dentist* } \\
\hline Toothache & $8(7.1 \%)$ & $5(7.5 \%)$ & $3(3.2 \%)$ & \multirow{4}{*}{-} \\
\hline Routine exam & $5(4.5 \%)$ & $1(1.5 \%)$ & $4(4.3 \%)$ & \\
\hline Dental extraction & $43(38.4 \%)$ & $23(34.3 \%)$ & $20(21.5 \%)$ & \\
\hline Need of prosthesis & $33(29.5 \%)$ & $6(8.9 \%)$ & $27(29.0 \%)$ & \\
\hline \multicolumn{5}{|c|}{ Perceived need for treatment* } \\
\hline No & $73(55.7 \%)$ & $23(34.3 \%)$ & $50(53.8 \%)$ & \multirow{2}{*}{$P=.006$} \\
\hline Yes & $58(44.3 \%)$ & $32(47.7 \%)$ & $26(27.9 \%)$ & \\
\hline
\end{tabular}

${ }^{*}$ data were not available in all cases; ${ }^{\dagger}$ of those practicing oral hygiene.

A minority had visited a dentist in the preceding three months, most commonly for dental extraction. Only 58 participants perceived a need for treatment; however, clinical examination revealed the need for at least some dental treatment in all 160 cases.

In the bivariate analysis, only sex, age, and general literacy level were significantly associated with the DMFT (Table 3 ). Females presented with a higher DMFT. However, this variable was confounded by age (i.e., the mean age of females was higher than that of males). In the multiple regression analysis, age $(\beta=0.11 ; p=.005)$, general literacy level $(\beta=-0.79$ for each additional year of schooling; $P=.003)$, and practice of any type of oral hygiene $(\beta=2.5 ; P=.02)$ were independently significantly associated with the DMFT. However, only $13 \%$ of the variance of the DMFT could be accounted for by these three independent variables $\left(R^{2}=\right.$ $0.13)$.

A lower DMFT was observed among individuals who performed their own oral hygiene and used a toothbrush. However, these and other variables regarding oral hygiene habits (such as practicing any type of oral hygiene, frequency of oral hygiene, cleaning the tongue, and regular tooth brushing after meals) did not show any significant association with the DMFT. 
TABLE 3: Bivariate analysis of variables associated with the number of decayed, missing, and filled teeth (DMFT) in institutionalized older people in northeast Brazil.

\begin{tabular}{|c|c|c|c|}
\hline Variable & Mean DMFT & Standard deviation & $P$-value \\
\hline \multicolumn{4}{|l|}{ Sex } \\
\hline Male & 29.0 & 5.10 & \multirow{2}{*}{.03} \\
\hline Female & 30.5 & 3.31 & \\
\hline \multicolumn{4}{|l|}{ Age (years) } \\
\hline $65-74$ & 28.7 & 5.27 & \multirow{3}{*}{.05} \\
\hline $75-84$ & 30.3 & 3.64 & \\
\hline$\geq 85$ & 31.5 & 1.12 & \\
\hline \multicolumn{4}{|l|}{ Marital status } \\
\hline Single/widower/divorced & 29.7 & 4.36 & \multirow{2}{*}{.91} \\
\hline Married & 29.6 & 4.45 & \\
\hline \multicolumn{4}{|l|}{ Time in institution } \\
\hline $0-5$ years & 29.2 & 4.88 & \multirow{3}{*}{.17} \\
\hline $6-10$ years & 30.0 & 3.97 & \\
\hline$>10$ years & 30.5 & 3.39 & \\
\hline \multicolumn{4}{|l|}{ General literacy level } \\
\hline Illiterate & 30.8 & 3.14 & \multirow{2}{*}{.03} \\
\hline Literate & 29.6 & 4.14 & \\
\hline \multicolumn{4}{|l|}{$\begin{array}{l}\text { Practices any type of oral } \\
\text { hygiene }\end{array}$} \\
\hline No & 28.4 & 5.07 & \multirow{2}{*}{.24} \\
\hline Yes & 29.9 & 4.25 & \\
\hline \multicolumn{4}{|l|}{ Who does the oral hygiene } \\
\hline Older people & 29.6 & 4.48 & \multirow{2}{*}{.08} \\
\hline Carer & 30.9 & 3.24 & \\
\hline \multicolumn{4}{|l|}{ Use of tooth brush } \\
\hline No & 30.4 & 3.69 & \multirow{2}{*}{.06} \\
\hline Yes & 29.1 & 4.84 & \\
\hline \multicolumn{4}{|l|}{$\begin{array}{l}\text { Received health education } \\
\text { on oral hygiene }\end{array}$} \\
\hline No & 29.0 & 5.35 & \multirow{2}{*}{.18} \\
\hline Yes & 30.0 & 3.75 & \\
\hline \multicolumn{4}{|l|}{$\begin{array}{l}\text { Regular tooth brushing } \\
\text { after meals }\end{array}$} \\
\hline No & 29.1 & 4.59 & \multirow{2}{*}{.12} \\
\hline Yes & 30.2 & 4.13 & \\
\hline \multicolumn{4}{|l|}{$\begin{array}{l}\text { Frequency of oral hygiene } \\
\text { per day }\end{array}$} \\
\hline None & 28.4 & 5.07 & \multirow{4}{*}{.41} \\
\hline Once & 29.8 & 4.05 & \\
\hline Twice & 30.5 & 3.25 & \\
\hline Three times or more & 28.8 & 5.76 & \\
\hline
\end{tabular}

\section{Discussion}

Our study shows that the experience of dental caries (as represented by the DMFT index) in institutionalized older people in northeast Brazil is extremely high. The data also found that there were insufficient oral hygiene practices in this special population. Similar to most studies on institutionalized older people throughout the world [3-14], a high proportion of the population was edentulous.

The oral health status in the general older people population has been addressed increasingly in the past years, but the oral health of institutionalized older people and underprivileged populations continues to be a neglected issue $[1,20-23]$. The DMFT varies considerably not only 
between different socioeconomic groups, but also between different countries and cultures, and it is consistently higher in institutionalized people than among community-dwelling populations [4-17, 24]. For example, in Hong Kong, the mean DMFT index was 21.4 in institutionalized as compared to 17.7 in noninstitutionalized older people [24]. A small number of other studies from southern Brazil indicate that the oral health status of institutionalized as well as noninstitutionalized older people was also very poor $[15,17$, 25]. In southern Brazil, the DMFT in institutionalized was as high as 30.8 [15], which was similar to our study population from the northeast $(\mathrm{DMFT}=29.7)$. A representative national survey made in 2002/2003 on oral health conditions in the Brazilian population revealed a mean DMFT of 27.8 in community-dwelling older people [18].

Oral hygiene practices in the study population were inadequate, and this group of older people had poor access to dental health care. In all residents, a need for treatment by a dentist was detected by the clinical assessment, but only $44 \%$ had perceived that need. In Brazil, residents in these institutions tended to have very poor socioeconomic conditions, and the findings of the present study indicate that dental health care for the poorest and oldest in society needs more attention. Initially, these issues were discussed with the director of the institution, and a dentist now regularly performs preventive and curative oral health care activities. Residents also received free treatment after the study.

On the public health level, health education programs focusing on the special needs of these populations are mandatory. An integrated approach is needed, and oral health education should include all stakeholders [26]. Additionally, it is necessary to implement curative and rehabilitation measures in these populations to reduce the need for future dental treatment [27].

Due to the cross-sectional design, causal and temporal relationships between independent variables and DMFT could not be clearly established. In addition, a possible limitation of the study was that it was conducted in a single institution, although this was the largest nursing home in the state of Ceará.

In conclusion, this study shows that the dental status of institutionalized older people in the state of Ceará is very poor. There is a lack of perceived need for dental services and of adequate oral self-care. Dental health education is also needed focusing on the special needs of this neglected and socioeconomically deprived population to improve their quality of life.

\section{Acknowledgments}

L.R.G. held a scholarship from the National Council for Scientific and Technological Development (Conselho Nacional de Desenvolvimento Científico e Tecnológico - CNPq), Brazil. The authors thank the Board of Directors of "Lar Torres de Melo" for their kind cooperation. The assistance of the staff of the nursing home is also gratefully acknowledged. We wish to especially thank all the residents of the nursing home, who participated in this study.

\section{References}

[1] P. E. Petersen and T. Yamamoto, "Improving the oral health of older people: the approach of the WHO Global Oral Health Programme," Community Dentistry and Oral Epidemiology, vol. 33, no. 2, pp. 81-92, 2005.

[2] S. R. da Silva and A. Valsecki Jr., "Evaluation of oral health conditions among the elderly in a Brazilian city," Revista Panamericana de Salud Pública, vol. 8, no. 4, pp. 268-271, 2000 (Portuguese).

[3] A. G. Ellis, "Geriatric dentistry in long-term-care facilities: current status and future implications," Special Care in Dentistry, vol. 19, no. 3, pp. 139-142, 1999.

[4] C. Stubbs and P. J. Riordan, "Dental screening of older adults living in residential aged care facilities in Perth," Australian Dental Journal, vol. 47, no. 4, pp. 321-326, 2002.

[5] R. Saub and R. W. Evans, "Dental needs of elderly hostel residents in inner Melbourne," Australian Dental Journal, vol. 46, no. 3, pp. 198-202, 2001.

[6] C. C. Wyatt, "Elderly Canadians residing in long-term care hospitals-part II. Dental caries status," Journal of the Canadian Dental Association, vol. 68, no. 6, pp. 359-363, 2002.

[7] A. Rao, P. Sequeira, S. Peter, and A. Rajeev, "Oral health status of the institutionalized elderly in Mangalore, India," Indian Journal of Dental Research, vol. 10, no. 2, pp. 55-61, 1999.

[8] E. Bitetti, A. Senna, and L. Strohmenger, "Oral health comparison between the institutionalized and non institutionalized elderly," Minerva Stomatologica, vol. 53, no. 9, pp. 507-516, 2004.

[9] I. F. Angelillo, G. Sagliocco, S. J. H. Hendricks, and P. Villari, "Tooth loss and dental caries in institutionalized elderly in Italy," Community Dentistry and Oral Epidemiology, vol. 18, no. 4, pp. 216-218, 1990.

[10] D. Triantos, "Intra-oral findings and general health conditions among institutionalized and non-institutionalized elderly in Greece," Journal of Oral Pathology and Medicine, vol. 34, no. 10 , pp. 577-582, 2005.

[11] V. Vucićević-Boras, A. Bosnjak, I. Alajbeg, A. CekićArambasin, and B. Topić, "Dental health of elderly in retirement homes of two cities in south Croatia- a cross-sectional study," European Journal of Medical Research, vol. 7, no. 12, pp. 550-554, 2002.

[12] T. King and D. Kapadia, "Oral health status and treatment needs of institutionalized elderly and disadvantaged population in Fiji (1997)," Pacific Health Dialog, vol. 10, no. 1, pp. 35-40, 2003.

[13] E. C. Lo, Y. Luo, and J. E. Dyson, "Oral health status of institutionalised elderly in Hong Kong," Community Dental Health, vol. 21, no. 3, pp. 224-226, 2004.

[14] G. Soh, Y. H. Chong, and G. Ong, "Dental state and needs for episodic care of institutionalized elderly in an Asian community," Social Science and Medicine, vol. 34, no. 4, pp. 415-418, 1992.

[15] R. M. Carneiro, D. D. da Silva, M. L. de Sousa, and R. S. Wada, "Oral health of institutionalized elderly in the eastern zone of São Paulo, Brazil, 1999," Cadernos de Saúde Pública, vol. 21, no. 6, pp. 1709-1716, 2005 (Portuguese).

[16] S. R. da Silva and A. Valsecki Jr., "Evaluation of oral health conditions among the elderly in a Brazilian city," Revista Panamericana de Salud Pública, vol. 8, no. 4, pp. 268-271, 2000 (Portuguese).

[17] J. Jorge Jr., O. P. de Almeida, L. Bozzo, C. Scully, and E. Graner, "Oral mucosal health and disease in institutionalized elderly in 
Brazil," Community Dentistry and Oral Epidemiology, vol. 19, no. 3, pp. 173-175, 1991.

[18] Brasil-Ministério da Saúde, "Projeto SB Brasil 2003Condições de saúde bucal da população brasileira 2002-2003," Resultados principais, Brasília, 2004.

[19] L. R. Gaião, M. E. L. de Almeida, and J. Heukelbach, "Epidemiology of tooth decay, periodontal diseases, use and need of prostheses in the elderly living in a nursing home in the city of Fortaleza, State of Ceará (Brazil)," Revista Brasileira de Epidemiologia, vol. 8, no. 3, pp. 316-323, 2005 (Portuguese).

[20] A. H. Guay, "The oral health status of nursing home residents: what do we need to know?" Journal of Dental Education, vol. 69, no. 9, pp. 1015-1017, 2005.

[21] A. H. Guay, "Improving access to dental care for vulnerable elders," Journal of Dental Education, vol. 69, no. 9, pp. 10451048, 2005.

[22] A. H. Guay, "Access to dental care: solving the problem for underserved populations," Journal of the American Dental Association, vol. 135, no. 11, pp. 1599-1605, 2004.

[23] A. G. Ellis, "Geriatric dentistry in long-term-care facilities: current status and future implications," Special Care in Dentistry, vol. 19, no. 3, pp. 139-142, 1999.

[24] A. S. McMillan, M. C. M. Wong, E. C. M. Lo, and P. F. Allen, "The impact of oral disease among the institutionalized and non-institutionalized elderly in Hong Kong," Journal of Oral Rehabilitation, vol. 30, no. 1, pp. 46-54, 2003.

[25] A. C. Pereira, R. A. Castellanos, S. R. da Silva, M. G. Watanabe, D. P. Queluz, and M. C. Meneghim, "Oral health and periodontal status in Brazilian elderly," Brazilian Dental Journal, vol. 7, no. 2, pp. 97-102, 1996.

[26] D. W. Matear, "Demonstrating the need for oral health education in geriatric institutions," Probe, vol. 33, no. 2, pp. 66-71, 1999.

[27] Y. Shimazaki, I. Soh, T. Koga, H. Miyazaki, and T. Takehara, "Relationship between dental care and oral health in institutionalized elderly people in Japan," Journal of Oral Rehabilitation, vol. 31, no. 9, pp. 837-842, 2004. 


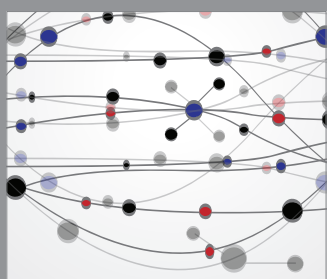

The Scientific World Journal
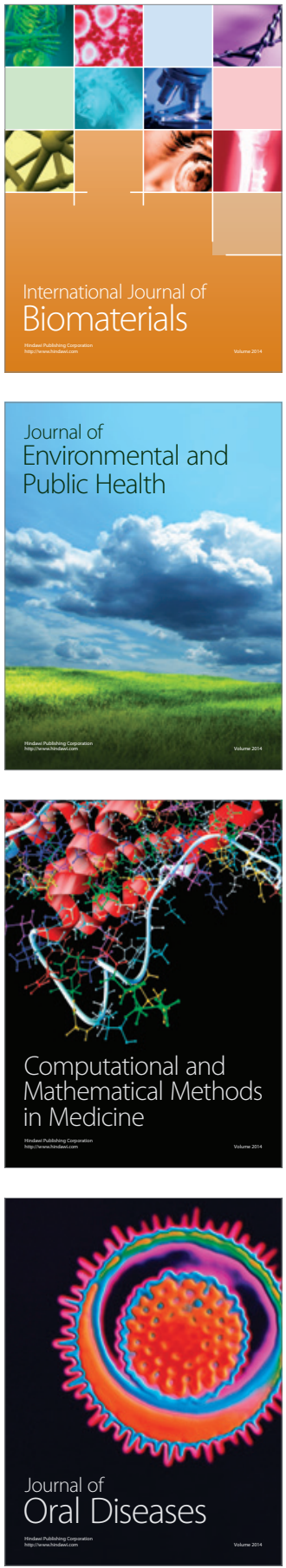
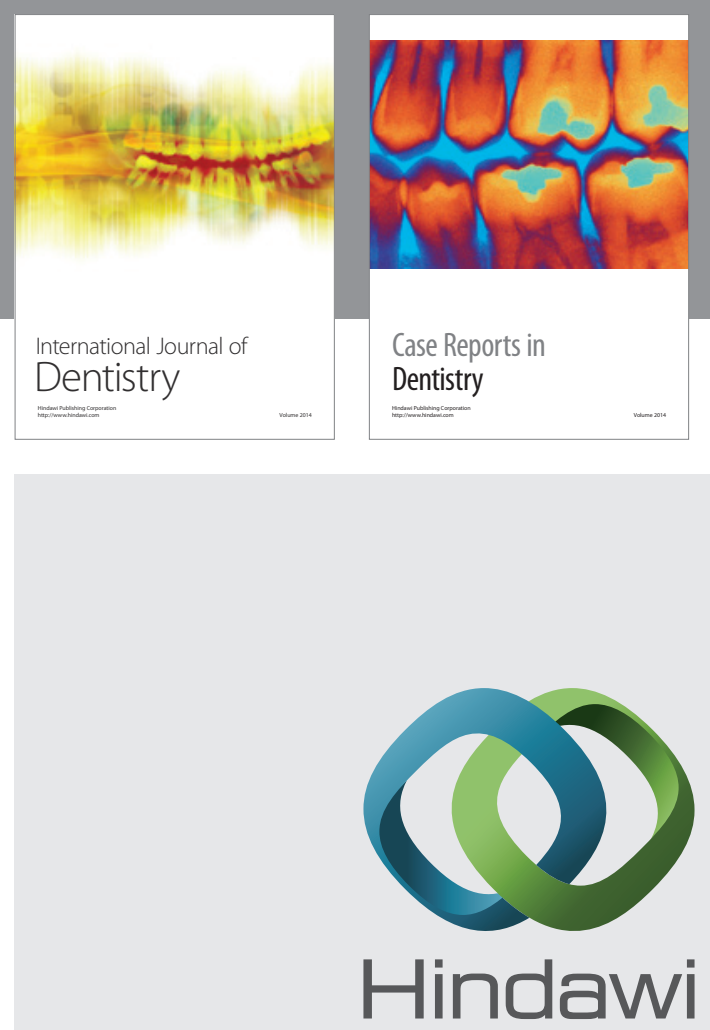

Submit your manuscripts at

http://www.hindawi.com
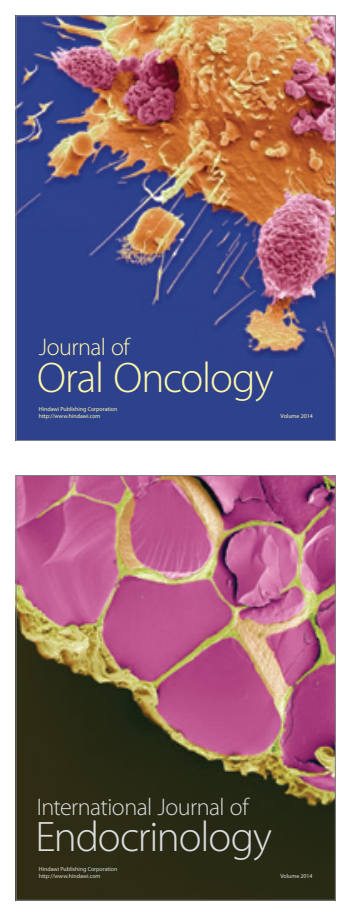
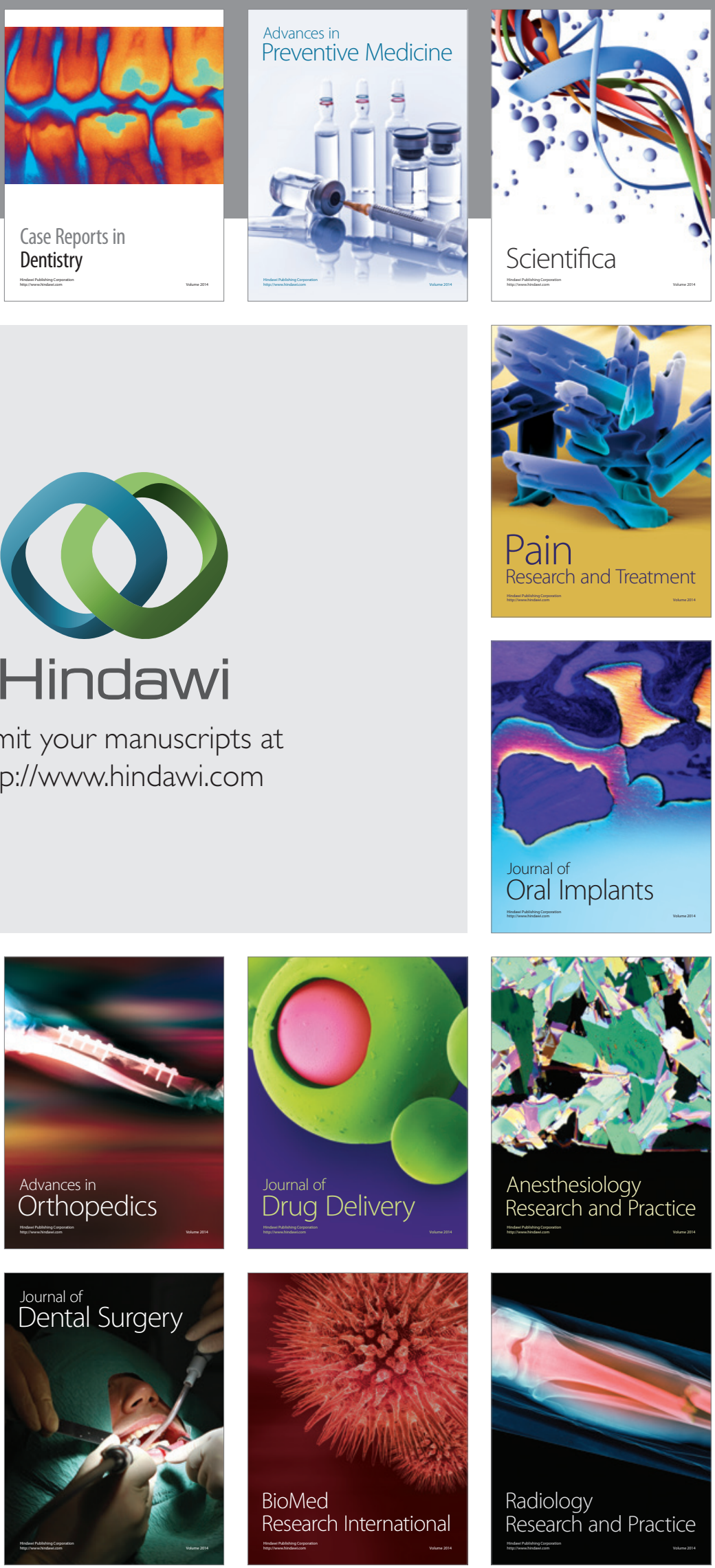